\title{
Prospects for using mineral resources of southern Russia in aquaculture
}

\author{
Nina Abrosimova ${ }^{1,{ }^{*}}$, Kseniya Abrosimova ${ }^{2}$, Ekaterina Abrosimova ${ }^{1}$, Yuri Kokhanov ${ }^{1}$, \\ and Tatyana Arutyunyan ${ }^{1}$ \\ ${ }^{1}$ Don State Technical University, Gagarin sq., 1, Rostov on Don, 344003, Russia \\ ${ }^{2}$ Kuban State University, st. Stavropolskaya, 149, Krasnodar, 350040, Russia
}

\begin{abstract}
In aquaculture, the application of natural mineral raw materials with their ion exchange and adsorption properties is on the increase, which contributes to an increase in the economic performance of fish farms. The Southern Federal District in Russia, the leader in fish production, has active deposits of zeolites, bentonites and glauconites classified as high-grade mineral raw resources containing up to $70 \%$ of active components, though almost not used in fish farming. Our research focuses on studying the productive and biological effect of mineral raw materials of the Southern Federal District (Russia) as a mineral supplement to fish feeds (the case of the zeolites from the Proval'skoe deposit in Rostov Region). Zeolite in the amount of 3\% was introduced into the starter feeds for sterlet. The studies have shown that zeolites from the Proval'skoye deposit applied to feeds contribute to an increase in weight growth $(\mathrm{p} \leq 0.05)$ and survival of sterlet, to a feed conversion decrease and an increase in protein and energy efficiency ratio, positively affect the composition of fatty acids and the stability of lipid peroxidation. The results obtained suggest the use of mineral raw materials from the Southern Federal District as a dietary component.
\end{abstract}

\section{Introduction}

Successfully developing aquaculture in the South of Russia requires the development of new and improving the existing technologies for new intensive methods of fish cultivation. Feeds and feeding organization, as well as stable optimal conditions of fish maintenance, are essential in this case.

In modern conditions, water ecosystems experience the increasing anthropogenic pressure. Hydraulic engineering, especially small dams, untreated or insufficiently treated industrial and agricultural runoff, and intensive water consumption negatively affect the water balance of water sources, their hydrochemical and hydrological regimes due to the accumulation of various pollutants, such as heavy metals, pesticides, etc. Accumulated in the body of hydrobionts, these substances cause significant damage to both aquaculture and fisheries in general, impairing the reproductive quality, growth and physiological condition of fish. With resistance reduced to changing conditions of the external and internal

\footnotetext{
* Corresponding author: abrosimovana@yandex.ru
} 
environment, they provoke various diseases. Moreover, as a source of human food, such fish do not guarantee food security. Consequently, the optimization of fish breeding and cultivation, related to the problem of improving their external and internal environment, has become the primary task of fisheries science.

One of the important directions of fisheries technologies optimization is the use of mineral raw materials, which are characterized by sorption and ion exchange properties. These natural sorbents include zeolites, glauconites, bentonite clays, and other natural mineral sorption agents. They are promising objects for the effective application, since they are relatively easy to integrate into various existing technologies, as well as serve as the basis for creating new ones.

Natural zeolites are framework aluminosilicates with high thermal stability, acid resistance, sorption and ion exchange activity.

The chemical composition of natural zeolites mainly consists of compounds of $\mathrm{Si}, \mathrm{Ca}$, $\mathrm{Al}, \mathrm{Na}, \mathrm{K}, \mathrm{Mn}, \mathrm{P}, \mathrm{Cu}, \mathrm{Mg}, \mathrm{Co}, \mathrm{Zn}, \mathrm{B}$, and Ti.

In practice, the ability of zeolites to absorb metal and ammonium ions from aqueous solutions is most widely used [1-2]. In this case, the selectivity of zeolites to various cations is of exceptional practical interest, which is due to the ability to exchange them for cations of their own crystal lattice.

Bentonite is a mixture of natural aluminosilicate minerals, the base of which is montmorillonite.

The chemical composition of natural bentonite clays in the rocks of various deposits varies and depends on the composition of the initial volcanic material. They contain a large set of macro- and microelements vital for the body, such as $\mathrm{Cu}, \mathrm{Zn}, \mathrm{Mn}, \mathrm{Co}, \mathrm{Ag}, \mathrm{Ca}, \mathrm{Mg}$, $\mathrm{Cr}, \mathrm{J}, \mathrm{Fe}$, and the salts of alkaline and alkaline earth metals as well.

Bentonites are characterized by hydrophilicity, ion exchange ability, and surface activity that positively affects the absorption of feed nutrients in the animal's body [3]. The use of bentonite clays as a source of macro- and microelements and biologically active components to optimize the feeding of farm animals is on the increase.

High adsorption of opportunistic microflora and mycotoxins by bentonites is also registered [4-5].

Glauconites are clay aluminosilicates of layered structure and variable composition with a high content of $\mathrm{Fe}+2, \mathrm{Fe}+3, \mathrm{Ca}, \mathrm{Mg}, \mathrm{K}, \mathrm{F}$, and they also contain more than twenty trace elements, such as $\mathrm{Cu}, \mathrm{Ag}, \mathrm{Co}, \mathrm{Mn}, \mathrm{Zn}, \mathrm{Mo}, \mathrm{Cr}$, and others. Glauconites have high absorption and cation exchange properties, since macro- and microelements are easily replaced by those elements that are in excess in the environment. These properties of glauconites contribute to their wide application in various fields of economy [6].

In the structure of consumption of natural agromineral raw materials, both in the Russian Federation and abroad, half of the production goes to agriculture (increasing soil fertility, restoring deflated land and deodorizing livestock premises, to increase the shelf life and preserve the quality of organic fertilizers, for feeding farm animals). Other areas of application are the paper industry, building materials, the food industry, where adsorption and ion exchange technologies are used, and the communal services and public utilities.

Many researchers note the importance of zeolites as the most promising objects for sustainable development of aquaculture [7]. With a high probability, this characteristic can be attributed to other natural minerals. This natural mineral resource is still the mineral of the future.

Most modern works on the use of mineral raw resources as a feed additive are devoted to improving the maintenance and feeding of farm animals, in particular, cattle and poultry [5-9].

At the same time, this natural raw material, due to its sorption and ion exchange properties, is actively introduced in aquaculture, especially in intensive cultivation methods, 
where the issue of balance between rational feeding with feeds with high protein content and the metabolites released by fish in the form of ammonia is acute.

Positive results were obtained when zeolites were introduced into the diet of sturgeon species, carp and Nile tilapia. It was ascertained that feeds with zeolites increase the growth rate of fish, improve the dietary properties of feeds and the physiological state of fish [1013]. Zeolites introduced into the diet of the Nile tilapia increase the economic efficiency of fish cultivation [13].

Bentonites as a feed additive are used in animal husbandry in natural and acid-activated forms. Experimental feeding of the African catfish Clarias gariepinus with feeds enriched with activated and non-activated bentonites has indicated an improvement in the biological and productive actions of these feeds, as well as an improvement in hydrochemical indicators during fish cultivation [9].

With regard to glauconites, the prospect of their application in accordance with their functional characteristics, as well as a feed additive, is evident [6]. As the basis of a feed additive, glauconite provides an increase in the daily growth of carp by more than $15 \%$ [14].

Optimization of wintering conditions for sterlet in ponds of 0.05 ha by using zeolites from the Pegasi and Shivyrtuin deposits characterized by high sorption and ion exchange capacity for ammonia and heavy metal ions, contributed to the localization of hydrogen sulfide zones and decreased the level of ammonium ions in ponds [15].

Bentonites due to their high adsorption capacity [3] are also an effective means for removing ammonium ions from water under intensive culture conditions.

The low cost of zeolites and bentonites makes them promising as ion exchangers for the use in installations with recirculation water supply (RAS).

Scientific research on the use of domestic zeolites, bentonites and glauconites in fish farming was mainly started in the 1980s. Despite the proven promise as a mineral feed additive, regulators of oxygen and acid-base regime, as well as the content of ammonium ions in the external and internal environment of fish, these studies are mostly exploratory in nature and are far from the level of industrial technologies. At the same time, in Russia and, in particular, on the territory of the Southern Federal District (SFD), deposits of mineral raw materials with sufficiently high qualitative and quantitative indices have been identified and studied.

According to the state cadastre of deposits on the territory of the Southern Federal District, existing deposits of zeolites, bentonites and glauconites are located in four regions of the Russian Federation [16]:

- zeolites: Provalskoye, Tarasovskoye, Vlasovskoye, Uspenskoye (Rostov Region), Kamennoyarskoye (Astrakhan Region).);

- bentonites: Yuzhno-Tarasovskoe (Rostov Region), Dolgovskoye and Melovskoye (Volgograd Region), Kurtsovskoe (Republic of Crimea);

- glauconites: Sobolevskoe, Zhuravskoe and Nizhne-Zhuravskoe (Rostov Region), Maximovskoe (Volgograd Region).

Despite the positive productive and biological effect of natural mineral raw materials as a feed component and their unique ion exchange and adsorption-desorption properties, a number of issues remain unclear:

- exchange capacity of raw materials, which depends on their origin and external and internal structure. These features determine selectivity to various substances and their use as industrial sorbents;

- concentrations set as a mineral feed additive for various fish species;

- standards for the use as sorbents and ion exchangers for water purification in various systems with intensive fish farming methods; 
- periods of reclamation of raw materials when used as sorbents for efficient and uninterrupted water treatment;

- influence of mineral raw materials due to their active ion exchange and adsorptiondesorption properties on free radical processes of the animal's organism.

\section{Research Goal}

The goal of our research is to study the effect of zeolites (Provalskoye deposit in Belokalitvinsky District, Rostov Region, Russia) on free radical processes in fish by the indices of antioxidant protection (the case of the Don sterlet reared under conditions of intensive aquaculture with controlled and regulated reproduction).

\section{Materials and Methods}

The studies were carried out under the conditions of a scientific and industrial experiment. To level the factor of different quality in the experiments, we used sterlet prelarvae hatched during the first three hours.

The larvae and fry were kept in plastic tanks with the area of $4 \mathrm{~m}^{2}$ with a circular water flow and an initial stocking density of 15,000 individuals per a tank.

The larvae and fry of sterlet in the experiment and control were fed according to the common method, taking into account the fish weight and water temperature. At the stage of mixed feeding, the prelarvae were fed with grains of 0.1-0.2 $\mathrm{mm}$ in size, 5-7 times during the daytime and a daily diet of $20-30 \%$ of body weight. As the sterlet grew, the size of the feed increased. From the complete transition of larvae to exogenous feeding up to $100 \mathrm{mg}$ weight, they were fed with fines of $0.2-0.4 \mathrm{~mm}$, the fry of $100 \mathrm{mg}$ to $300 \mathrm{mg}$ ate feed of 0.4-0.6 mm size, the fries of 300 to $1000 \mathrm{mg}$ weight consumed grains of $0.6-1.0 \mathrm{~mm}$. The feeding frequency was 10-12 times during the period, the daily ration amounted to $20-30 \%$ of the fry weight. When the fry reached an average weight of $1 \mathrm{~g}$, they were transferred to crumbs of $1.0-1.5 \mathrm{~mm}$ in size with a feeding frequency of $8-10$ times during the daytime and a daily ration of $7 \%$ of the fish weight.

The experimental and control feeds were based on fish meal and a mixture of fish meal and sunflower meal hydrolysates in a 1:1 ratio. In terms of the component composition, the experimental feed differed from the control one by the additional introduction of $3 \%$ zeolite from the Proval'skoe deposit, which, in terms of its adsorption and structural properties, was classified as a raw material similar to high-grade zeolites with $70 \%$ of active components.

The introduction of zeolite did not significantly affect the balance of the protein and carbohydrate parts of those feeds. Therefore, the level of protein in them was 51.3-51.8\%, the concentration of fat amounted to $8-8.1 \%$, and that of carbohydrates made up to 29.8 $30.1 \%$. Zeolite was added to the experimental feed in the form of flour with the fineness of $<0.01 \mathrm{~mm}$.

We studied weight, growth rate, survival rates, Fulton's condition index (Fulton coefficient of fatness), feed costs per unit of gain, total biochemical composition of feed and fry, $₫ 3$ and $₫ 6$ fatty acid levels, hydroperoxides such as malondialdehyde (MDA) and diene conjugates (DC) and natural antioxidants, namely, superoxide dismutases (SOD) and $\alpha$-tocopherol.

We carried out general chemical analysis of feed and fish according to standard methods [17]. They included the determination of moisture by drying at $\mathrm{T}=105^{\circ} \mathrm{C}$, of fat by extraction in a Soxhlet apparatus (extractor), crude protein - by calorimetric determination of nitrogen multiplied by a coefficient of 6.25 , with Nessler's reagent 
applied. The ash content was determined by burning the test material in a muffle furnace at $\mathrm{T}=500{ }^{\circ} \mathrm{C}$, the amount of carbohydrates was determined by the difference between the sum of all substances in the sample and the sum of protein, fat, and ash.

To separate lipids into classes, the method of thin layer chromatography was applied, with their preliminary extraction according to Folch [17]. A fixed layer of silica gel "LS $5 / 401 \mathrm{~m} \mathrm{0"} \mathrm{(Chemapol)}+13 \%$ gypsum was used as a sorbent. Distillation of lipids was carried out in the following solvent system - hexane: diethyl ether: glacial acetic acid in a ratio of 80:20:2.

The assessment of lipoid phosphorus was carried out according to the method by S. Isao et al. [17].

Fatty acids were determined by gas-liquid chromatography on a Tsvet- 5 chromatograph. Lac 2R-446 - 27\% was used as a stationary middle-polar phase. The identification of fatty acids was carried out by comparing the graphs of the dependence of the logarithms of the retention volumes on the chain length of carbon atoms. Standard mixtures of "Sigma-1891 " and "Sigma-189-6" fatty acid methyl esters were used as taps.

The content of diene conjugates was estimated by the characteristic ultraviolet absorption spectrum of a lipid solution in a methanol:hexane solvent system in a 5:1 ratio. Malonic dialdehyde was determined in the reaction with thiobarbituric acid [18]. The activity of superoxide dismutase (SOD) was determined by the hydroxylamine method [19], of $\alpha$-tocopherol - by the fluorometric method [20].

The results were processed statistically using Microsoft Excel programs. To determine the reliability of the differences in features, we used Student's t-test and the probability of differences $(\mathrm{P} \leq 0.05)$.

\section{Research Results and Discussion}

Feeding of sterlet larvae started at the age of 14 days after transition to active feeding and with an average weight of $28 \pm 1.0 \mathrm{mg}$. After 32 days, the average weight of the experimental fry reached $1654 \pm 96 \mathrm{mg}$, the control ones $-1389 \pm 95 \mathrm{mg}$, with significant differences of $\mathrm{P}<0.05$ and close Fulton fatness indicators $-0.63 \pm 0.01$ and $0.66 \pm 0.02$, respectively. The survival rate of fish in the experiment exceeded the control variant by $16 \%$. Feed costs (feed ratio) in the experiment were $0.7 \mathrm{~g} / \mathrm{g}$ gain, in control $-1.2 \mathrm{~g} / \mathrm{g}$ gain.

The established significant differences in weight, a higher survival rate of juveniles with a decrease in feed costs by 0.5 units per unit of growth indicate an increase in the productivity of feed enriched with zeolite, which is confirmed by such indices of feed conversion as protein efficiency ratio and energy efficiency ratio. These indices characterize the amount of protein and feed energy transformed in the fish tissues.

Fish, especially larvae and fry, are distinguished by a high need for protein that they actively use not only in plastic metabolism, but also in the energy exchange processes, which is associated with the desire of a rapidly growing organism to maintain internal homeostasis. Therefore, when feeding the fish, the use of protein, predominantly, for growth is more important, while energy expenditures can be compensated at the expense of food lipids and carbohydrates. In our experiment with fry, the protein efficiency ratio and energy efficiency ratio of the feed for gain in total lipids and phospholipids were more than $30 \%$ and $20 \%$, respectively, while in the control they amounted to $22 \%$ and almost $16 \%$.

It should also be noted that in the experimental version, the number of fry weighing more than $1.5 \mathrm{~g}$ (Russian standard at controlled and regulated reproduction) exceeded this indicator in the control by $38 \%$.

The differences revealed in the productive action of feeds with zeolites and the control feed (growth, survival rates, feed ratio, protein efficiency ratio and energy efficiency ratio) predetermined the study of fatty acids spectrum in the muscles of fry. 
For the physiological nutritional value of the diet, the composition of $₫ 3$ and $₫ 6$ essential fatty acids and the balance between them in fish tissues are of particular interest. This is because a distinctive feature of fish lipids is a high content of $\omega 3$ and $\omega 6$ polyunsaturated fatty acids, especially $\omega 3$ acids.

We paid particular attention to unsaturated higher fatty acids: linoleic 18:2 $\omega 6$, arachidonic 20:4 $\omega 6$, linolenic 18:3 $\omega 3$, eicosapentaenoic 20:5 $\omega 3$, docosapentaenoic 22:5 $\omega 3$ and docosahexaenoic 22:6 $\omega 3$, which provide a number of functions in body, including resistance to certain stress factors.

Upon completion of feeding, some differences in the content of fatty acids in total lipids and phospholipids of the experimental and control fry were revealed.

The amount of $\omega 6$ fatty acids in the total lipids of the experimental fry was $10.7 \%$ less than in the control. The content of linoleic acid in them decreased by $9.7 \%$ (from $4.00 \%$ in the experiment to $4.39 \%$ in the control), arachidonic acid - by $19.8 \%$ (from $3.95 \%$ to $3.17 \%$, respectively) (Figure 1).

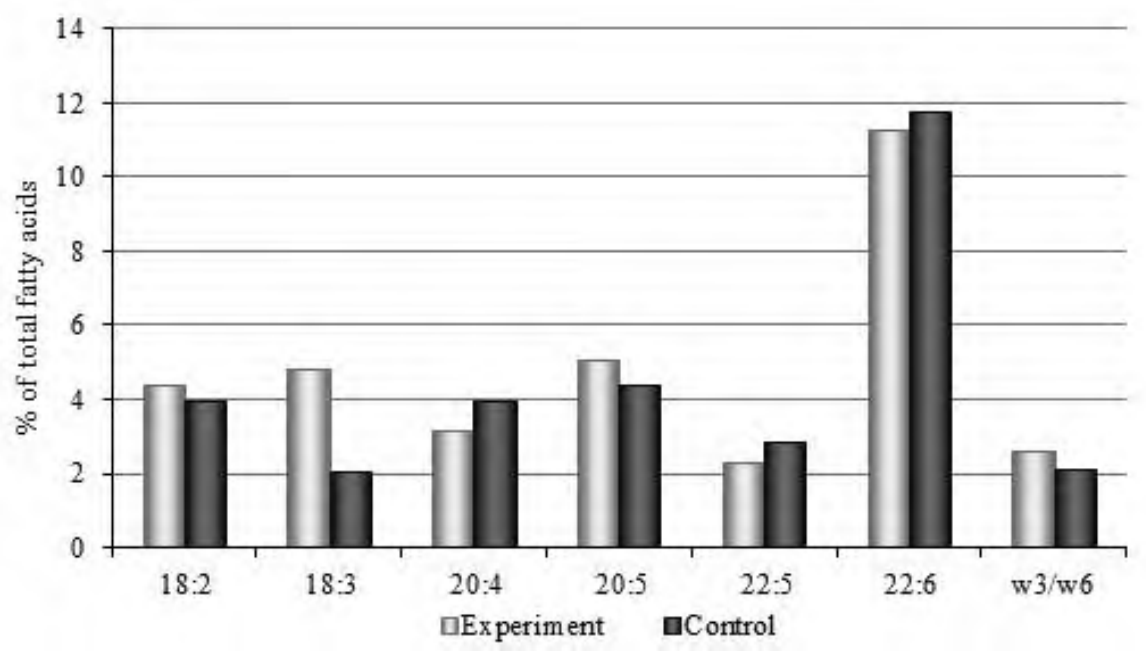

Fig. 1. Content of $\omega 6$ and $\omega 3$ acids in total lipids of sterlet fry, $\%$ of total fatty acids

The amount of $\omega 3$ in the total lipids of the experimental fry increased by $11 \%$ in comparison with the control. The increase in the amount of $\omega 3$ in total lipids was primarily due to an increase in the proportion of linolenic fatty acid by more than 2 times. The content of eicosapentaenoic acid increased by $15 \%$, and that of docosapentaenoic acid decreased by $20 \%$, while the level of docosahexaenoic acid was practically the same as in the control fish (11.29\% in the experiment, $11.76 \%$ in the control).

The balance of $\omega 3 / \omega 6$ acids in total lipids changed in favor of the experimental fry and amounted to 2.6 versus 2.1 in the control. 2).

Changes in the amount of fatty acids in phospholipids were similarly directed (Figure

In phospholipids, the amount of $\omega 6$ acids in the experimental fry was $12.3 \%$ less than in the control fry. With an equal amount of linoleic acid in fish of both variants, the level of arachidonic acid in the experimental fry decreased by $21.3 \%$ (in the control $-3.71 \%$, in the experiment $-2.92 \%$ ).

The amount of $\omega 3$ fatty acids in phospholipids of the experimental fry was $4.5 \%$ higher, as well as in total lipids, mainly due to linolenic acid, the level of which increased from $2.52 \%$ in the control to $5.33 \%$, i.e. almost twice. In the phospholipids of the experimental fry, the content of eicosapentaenoic acid increased slightly (by 3\%), and the content of 
docosahexaenoic acid increased by more than $10 \%$. The proportion of docosapentaenoic acid in phospholipids, as well as in total lipids, was $20 \%$ lower in the experimental fry.

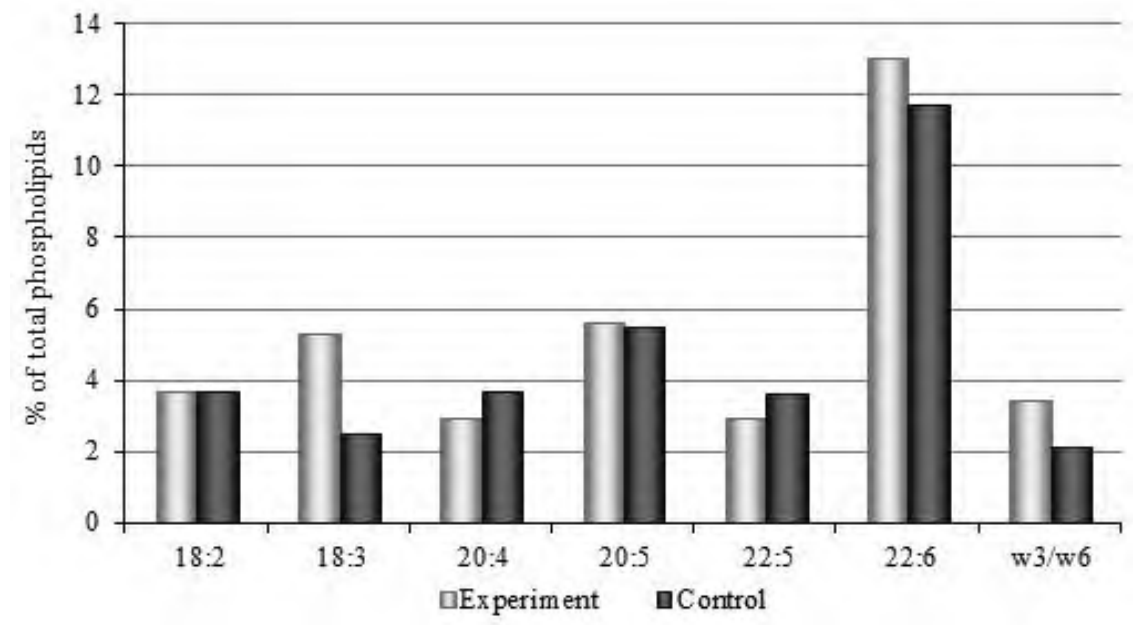

Fig. 2. Content of $\omega 3$ and $\omega 6$ acids in phospholipids of sterlet fry, $\%$ of total fatty acids

The $\omega 3 / \omega 6$ ratio of acids in phospholipids of the experimental fish exceeded the control variant by 1.3 units (3.4 in the experiment versus 2.1 in the control).

An increase in linolenic acid levels is associated with a decrease in linoleic acid, which is the biochemical precursor of linolenic acid. At the same time, despite some quantitative differences in other fatty acids and the balance between $\omega 3 / \omega 6$ acids in lipids, fry of both groups are in a satisfactory physiological norm.

At the same time, the increase observed in the content of docosahexaenoic acid in the phospholipids of experimental fish can be considered as a positive factor, since this acid is twice as effective as linolenic acid. Moreover, an increase in the $\omega 3 / \omega 6$ acid ratio in phospholipids of fry fed with zeolites by more than 1.5 times indicates an improvement in the stability of free radical processes, which is also confirmed by indices of lipid peroxidation in sterlet muscles.

The intensity of lipid peroxidation characterizes the adaptive and compensatory properties of the fish organism. Comparing the level of hydroperoxides formed during lipid peroxidation in sterlet fry, it should be noted that in experimental fish their level was lower than in the control (Figure 3). 


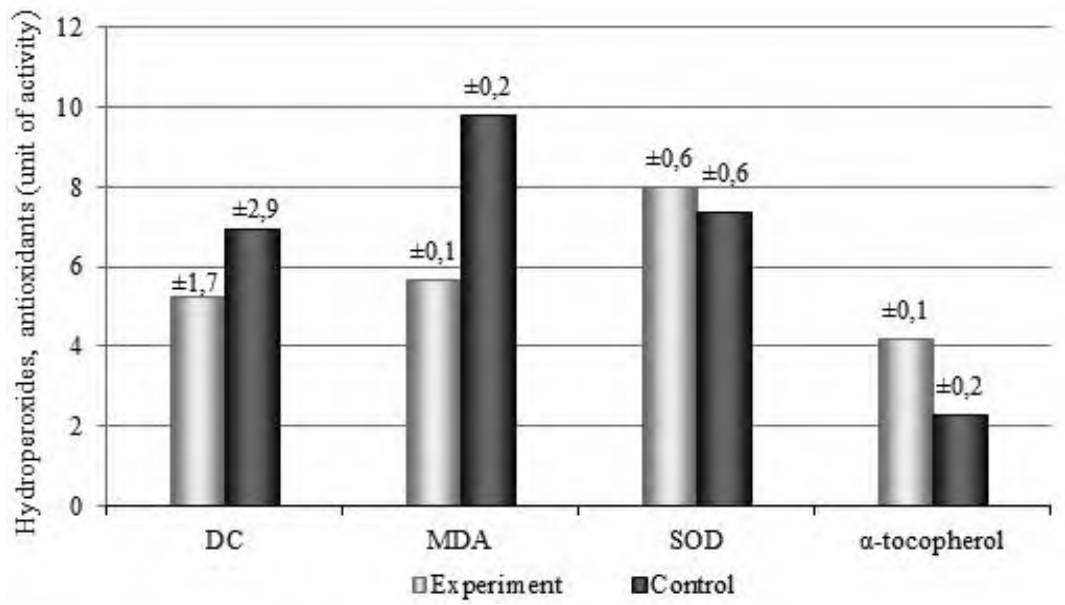

Fig. 3. Content of hydroperoxides and antioxidants in the muscles of sterlet fry, unit of activity

DC - diene conjugates; MDA - malondialdehyde; SOD - superoxidedismutase

Thus, the content of diene conjugates in the experimental fish was $24.6 \%$ less than in the control, and that of malondialdehyde by $41.8 \%$, with significant differences $(\mathrm{P}<0.01)$.

On the contrary, the activity of antioxidants increased: superoxide dismutase by $8.1 \%$ and $\alpha$-tocopherol by $82.6 \%$. Probably, in this case, in the stabilization of lipid oxidation (or FRO) processes, the greatest load fells on the enzymatic component of the antioxidant system - SOD. Small differences in SOD activity between the experimental and control fish were compensated by a significant increase in the activity of $\alpha$-tocopherol $(\mathrm{P}<0.05)$.

In conclusion, it should be noted that zeolites in the composition of starter feeds according to the complex of fish-biological and physiological-biochemical parameters have the most favorable effect on growth, survival rates, feed conversion, the formation of lipid and fatty acid status, antioxidant protection of the organism of young sterlet.

\section{Comment}

Natural zeolites of the Privolskoye deposit added to feed in an amount of $3 \%$ contribute to an increase in the productive and biological effect of starter feed for sterlet, providing the following biological and physiological-biochemical effects:

- increasing weight growth and survival;

- increasing the conversion of feed for plastic metabolism;

- normalization of fatty acid metabolism, restoration of the balance of fatty acids of the linolenic and linoleic series, corresponding to the physiological norm for sturgeon fry;

- stabilization of the activity of lipid peroxidation with a tendency to decrease its products against the background of an increased level of natural antioxidants.

\section{References}

1. Z. Ghasemi, I. Sourinejad, H. Kazemian, S. Rohani, Reviews in Aquaculture, 10(1), 75-95 (2018) doi:10.1111/raq.12148

2. M. Król, Crystals, Faculty of Materials Science and Ceramic, AGH University of Science and Technology, 10(7), 622 (2020) doi:10.3390/cryst10070622

3. D. Şahina, E. Sertaşib, M. Özc, Ü. Özc, Z. Karslia, O. Aral, Journal of Gaziosmanpasa Scientific Research, 7(3), 61-69 (2018) 
4. D. Hussain, Turkish Journal of Fisheries and Aquatic Sciences, 18, 1009-1016 (2018) doi:10.4194/1303-2712-v18_8_10

5. G. Rychen, G. Aquilina, G. Azimonti, V. Bampidis, M. de Lourdes Bastos, G. Bories, A. Chesson, P. S. Cocconcelli, G. Flachowsky, J. Gropp, B. Kolar, M. Kouba, M. Lopez-Alonso, A. Mantovani, B. Mayo, F. Ramos, M. Saarela, R. E. Villa, R. John Wallace, P. Wester, G. Martelli, D. Renshaw, G. Lopez-Galvez, S. L. Puente, EFSA Journal, 15(12), 5096, (2017) doi:10.2903/j.efsa.2017.5096.

6. S. K. Kurbaniyazov, N. A. Abdumutalip, Research in the field of natural Sciences, 5 (2012)

7. M. M. Abdel-Rahim, Fish \& Ocean Opj, 2(4), 555593 (2017) doi:10.19080/OFOAJ.2017.02.555593.

8. Recommendations for application of the zeolite containing feed additive "Terrabit" for farm animals and poultry (Belgorod, FGOU VPO BSAA, 2009)

9. A. M. Oluwaseyi, Application of dietary bentonite clay as feed addictive on feed quality, water quality and production performance of african catfish (Clarias gariepinus). Thesis (PhD)--Stellenbosch University (2016) https://scholar.sun.ac.za/handle/10019.1/98717 (Last accessed March 2016)

10. Yu. Bakaneva, A. Bychkova, N. Bakanev, Yu. Fedorovykh, FSBEI HE Astrakhan State Technical University, 1, 162-166 (2013)

11. J. Bakanova, A. Bychkov, N. Bakaev, Yu. Fedorovykh, FSBEI HE Astrakhan State Technical University, 5, 28-34 (2013)

12. A. Khodanazary, F. Boldaji, A.Tatar, B. Dastar, Turkish Journal of Fisheries and Aquatic Sciences, 13(3), 495-501 (2013) doi: 10.4194/1303-2712-v13_3_12

13. I. H. Ibrahim, A. F. F. El-Bab, M. T. S. El-Din, Abbassa Int. J. Aqua, 9(2), 253-287 (2016)

14. A. Kalilets, Patent RU №2648707 C2 Feed additive for fish and a method of its production №2016105479 №24 (2016)

15. N. A. Abrosimova, E. B. Abrosimova, K. S. Abrosimova, III National scientific and practical conference, Kazan, October 3-5, 8-12 (2018)

16. Natural sorbents, agromineral raw materials of the Rostov region, Territorial Fund of geological information for the southern Federal district (2010) http://www.tfgirostov.ru/index.php?itemid=9 (Last accessed March 2017)

17. N. A. Abrosimova, E. B. Abrosimova, K. S. Abrosimova, M. A. Morozova, Feed raw materials and biologically active additives for fish aquaculture facilities (Saint Petersburg, LAN, 2019)

18. E. N. Korobeinikova, Modification of the determination of lipid peroxidation in reaction with thiobarbituric acid. Laboratory Work, 7, 8-10 (1989)

19. Y. Kono. Archives of Biochemistry and Biophysics, 186(1), 189-195 (1983) doi:10.1016/0003-9861(78)90479-4

20. S. Taylor, M. Lamden, Al. Tappel, Lipids, 10(6), 407-412 (1976) doi:10.1007/BF02532898 